\title{
Classification of the Methods of Local Anesthesia and Special Features of Vascular-Diffuse Injection
}

\author{
Petrikas $A Z^{1}{ }^{*}$, Medvedev DV', Yakupova LA $^{2}$, Efimova OE ${ }^{2}$, Chestnyh EV ${ }^{2}$, Kulikova KV ${ }^{3}$ and Sazonova \\ $K A^{4}$
}

${ }^{1}$ Professor, Cathedra of Therapeutic Stomatology, Tver State Medical University, Russia

${ }^{2}$ Professor Assistant, Cathedra of Therapeutic Stomatology, Tver State Medical University, Russia

${ }^{3}$ Graduate Student, Cathedra of Therapeutic Stomatology, Tver State Medical University, Russia

${ }^{4}$ Student, Tver State Medical University, Russia

*Corresponding author: Arnold Petrikas, DMSc, DMD, PhD, Professor, Cathedra of Therapeutic Stomatology, Tver State Medical University, 170100, Tver, Sovetskaya, Str 4, Russia

\begin{abstract}
The main feature of modern injection methods of dental anesthesia is in the local venous spreading of the anesthetic in the near-toothed spongy substance of the bone and dental pulp. The vascular mechanism is controlled by the epinephrine anesthetic solution and patient vegetal system. Spongy dental anesthesia is universal, highly effective, relatively safe, easy to implement and increasingly widespread. Classification proposed by us is the division of injection methods of anesthesia into traditional diffuse: Infiltrative and conductive, and diffusevascular: Intraosseous, intraligamentary, intraseptal and intrapulparial.
\end{abstract}

\section{Keywords}

Dental anesthesia, Intravascular injection, Aspiration, Intraosseous anesthesia, Intraligamentous anesthesia, Epinephrine

\section{Introduction}

Earlier Petrikas AZ with assistants Yakupova LA, Medvedev DV, Efimova OE in their studies established the vascular mechanism as a leading component of spongy injection [1-4]. Considering the high efficiency, relative safety, versatility, ease of implementation and the increasing prevalence in the world with no serious complications, a modification of local anesthesia methods which has not changed significantly since $19^{\text {th }}$ century was proposed. The essence of this modification
Table 1: Modified classification of the methods of local anesthesia.

\begin{tabular}{|l|l|}
\hline Local anesthesia & \multicolumn{2}{l|}{} \\
\hline Diffuse & Vascular-diffuse \\
\hline Topical & Intraosseous \\
\hline Conductive & Intraligamentary \\
\hline Infiltrative & Intraseptal \\
\hline & Intrapulparial \\
\hline
\end{tabular}

is to divide the methods of anesthesia into diffuse and vascular-diffuse [5-7] (Table 1).

Types of spongy anesthesia significantly differ from traditional diffuse infiltration and conduction injections. All three types of spongy anesthesia spread in the spongy bone, i.e. they are both intraosseous and venous. Main types of spongy anesthesia are presented in Figure $1[6,7]$.

The effect of spongy anesthesia is given by the following mechanism (Figure 2). Using an injector with a needle, the local anesthetic solution is supplied to the external target on the oral mucosa which determines the name of the injection. The anesthetic solution delivery under pressure against the blood flow is blocked by $\alpha$-adrenoreceptors of arterioles which close the depot. The spongy intraosseous depot in the area of the internal target provides an effective concentration 


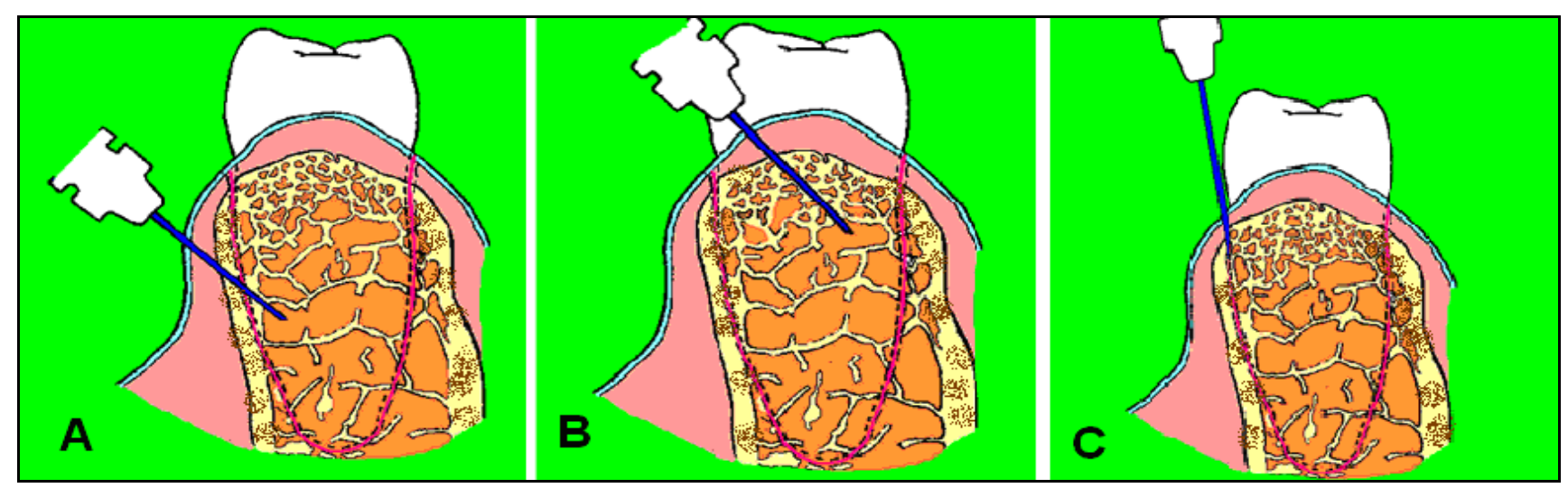

Figure 1: Types of spongy anesthesia: A) Special perforation of cortical plate, for example by a bur (intraosseous); B) Perforation of septa of cortical plate with manual needle movement (intraseptal); C) Insertion of a needle manually into periodontal ligament (intraligamentary).

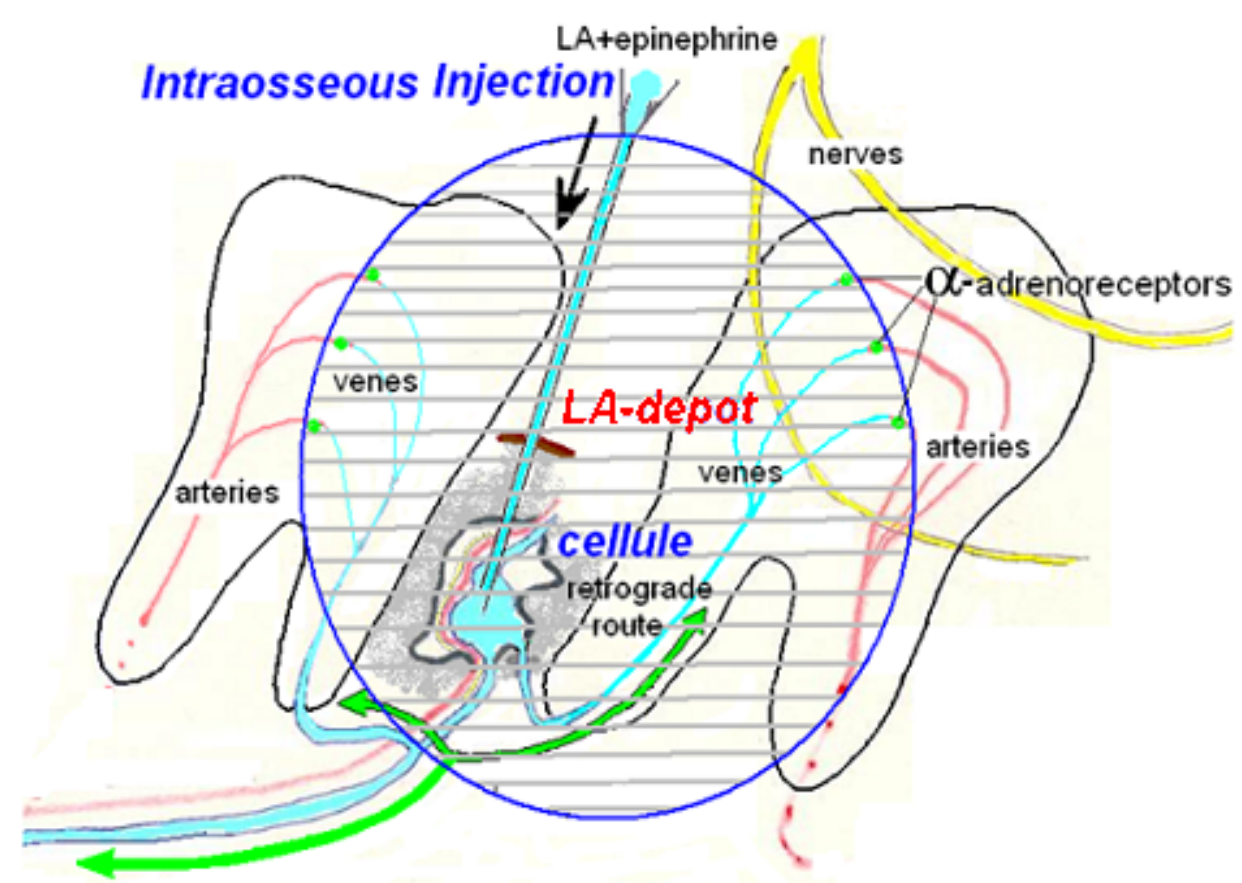

Figure 2: The establishment of an anesthetic depot during spongy anesthesia.

of the drug and the required volume. The volume dose of anesthetic is very important for the fast wetting of the required number of nerve receptors and Ranvier's interceptions located near the venous vessels [5-7].

\section{Special Features}

\section{Point 1}

Epinephrine should be present in local anesthetic solution. The need of epinephrine was proved by the experience of using intraligamentary and infiltrative anesthesia with mepivacaine without epinephrine in 65 healthy volunteers $[5,7]$.

Epinephrine did not close the depot of injectable flow of mepivacaine through the veins after spongy anesthesia with positive aspiration. Thus, mepivacaine did not create a depot and proceeded past the needleprobed area.

\section{Point 2}

The depot of the spongy spreading covers the periodont and pulp-a pulpo-periodontal complex of one or more often several teeth. On the average, intraosseous anesthesia blocks 2, 3 teeth [2], intraligamentary-3, 6 teeth [3]; intraseptal-2, 6 [4]. The number of blocked teeth depends on the dose of anesthetic. Mono tooth intraligamentary anesthesia is a common misconception. It is characteristic for the company Mielstone which gave the name to its advertised computer injector: STA-Single Tooth Anesthesia, considering one tooth anesthesia.

\section{Point 3}

The effect/time chart for spongy anesthesia is fundamentally differ from the classical, for example, infiltrative (Figure 3). The essence of the differences 


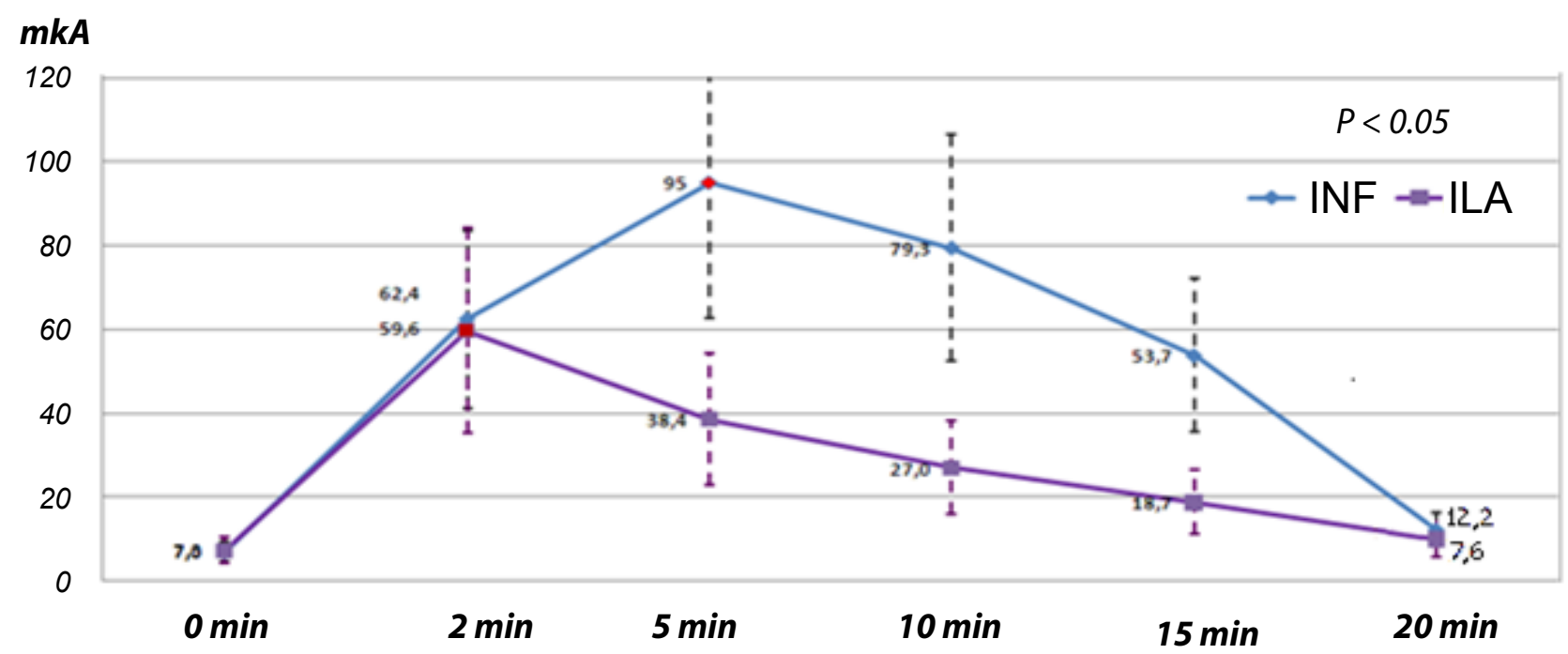

Figure 3: Chart: Effect/time after infiltrative and intraligamentary anesthesia of mepivacaine without adrenaline over the pain limit to an alternating electrical amperage of an intact upper lateral incisor in healthy volunteers [8].

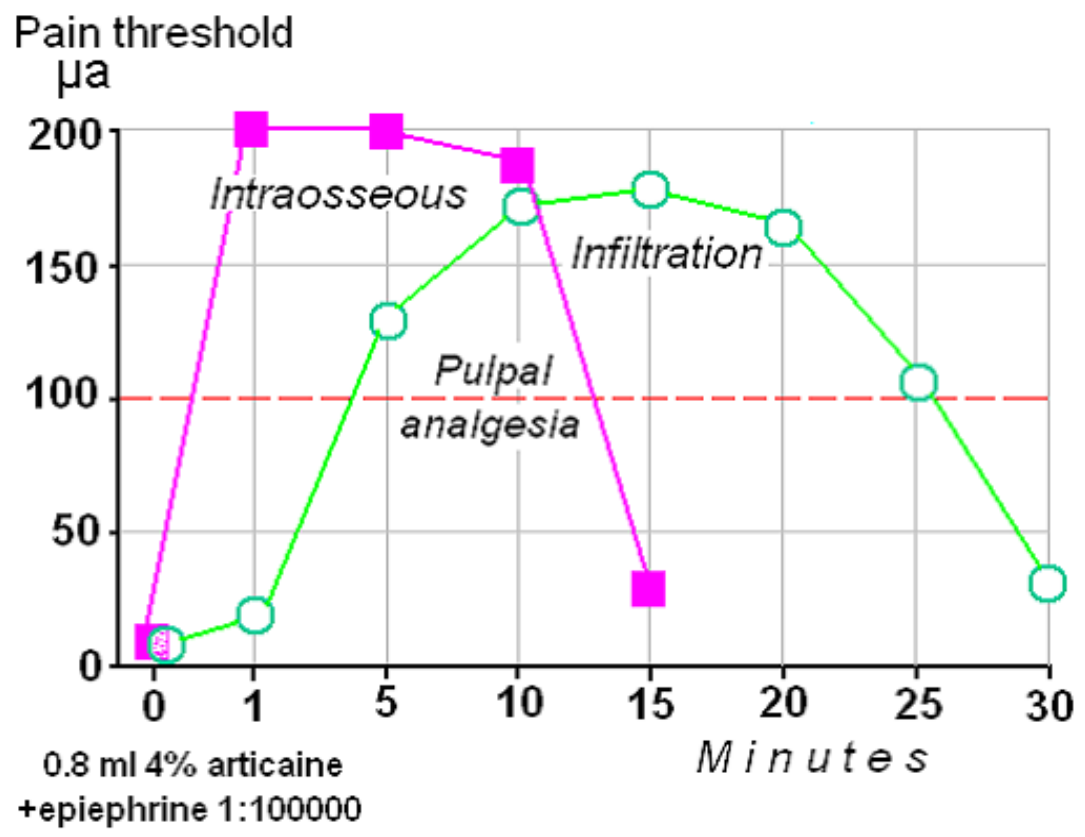

Figure 4: The effect of spongy anesthesia begins almost immediately reaching a maximum level and also end abruptly.

is that the effect from all types of spongy anesthesia begins almost 1) Immediately under the needle; 2) With a maximum depth; 3 ) End abruptly according to the "all or nothing" law. These are the main clinical differences from infiltration anesthesia.

\section{Point 4}

The dose of spongy anesthesia is approximately 2 times less than infiltrative anesthesia. This reduces the possibility of toxic reactions, but not psychogenic. Diffuse anesthesia expends its material on overcoming of tissue surrounding the tooth. This is clearly seen while the lower molars anesthesia. Spongy anesthesia became an alternative for mandibular injections [812]. Thus, the efficiency of spongy anesthesia greatly exceeds traditional injections. Clinicians appreciate spongy injections for the fast onset of anesthesia and its maximum depth (Figure 4).

\section{Point 5}

Positive aspiration in all spongy anesthesia occurs in approximately $90 \%$ of cases [11]. With intraligamental and intraseptal injection, positive aspiration was observed in the form of a thin stream with a frequency of $34 / 36 / 94.4 \%$ and $68 / 76 / 89.4 \%$, respectively. With intraosseous aspiration, the frequency of positive aspirations was observed in $68 / 76 / 89.4 \%$. This data demonstrates the venous mechanism of spongy injections and contradict the books of Malamed [13-15], where all additional anesthesia is represented by a zero frequency of positive aspirations. 


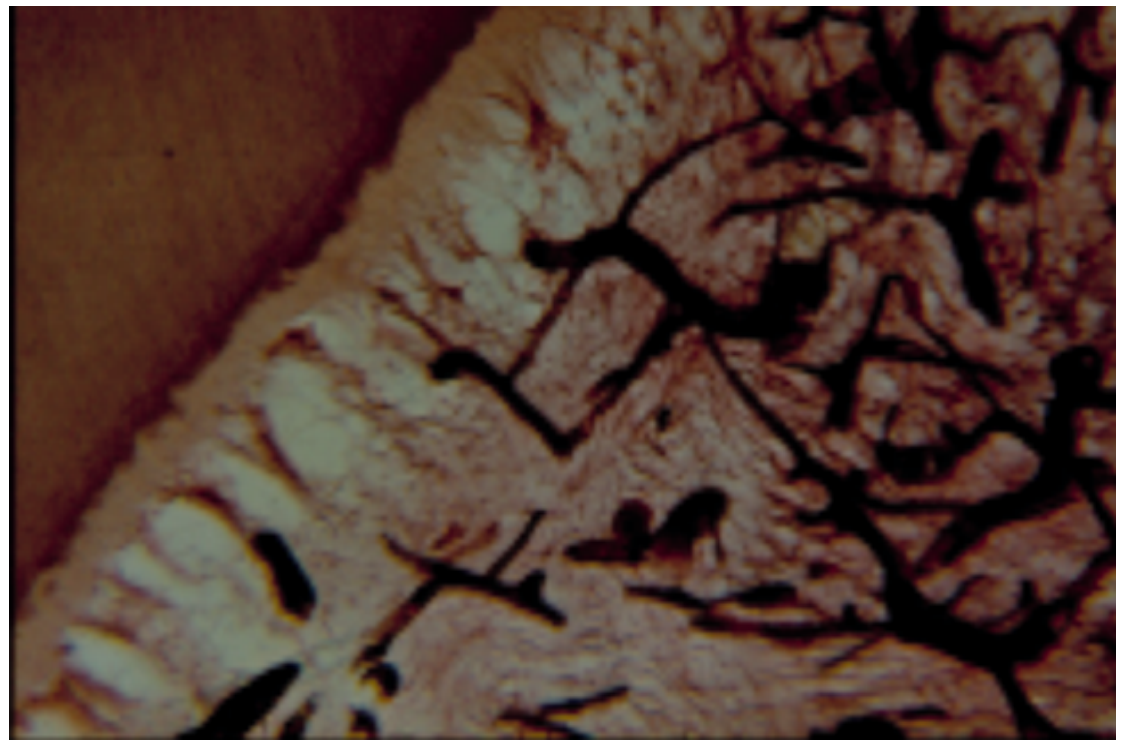

Figure 5: The spreading of staining agent in the pulp of the tooth after intraseptal anesthesia (corpse of 36 years woman) [8].

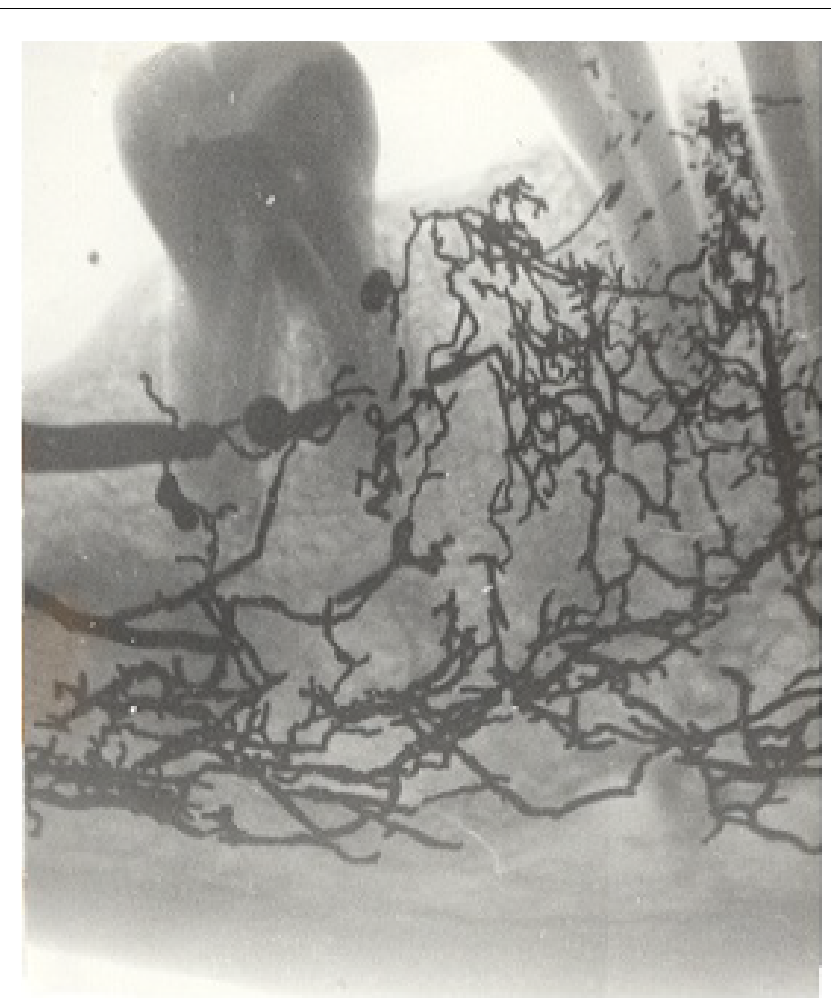

Figure 6: The spreading of mercury in the corpse after intraseptal injection between 44 and 43 .

\section{Point 6}

The histological picture after intraseptal injection of the dye (carcass) on the cadaver clearly demonstrates its venous spreading in the dental pulp because of the good vascular permeability of the carcass compared to mercury (Figure 5 and Figure 6). With spongy injections of mercury and dyes they almost always find the way to the vessels of the bone and pulp.

\section{Point 7}

Getting anesthetic into the vessel does not mean yet the development of the effect there. To activate the an- esthetic it is necessary to hold it there for the creation depot for a certain time-about 40 seconds [16].

Using of photoplethysmography proved that blood flow stops in the pulp after an intraligamentary injection of lidocaine with epinephrine for 15 minutes $[3,16]$.

\section{Point 8}

A quality feature of spongy anesthesia in contrast to classical, for example, mandibular is the absence of paresthesia of facial tissues: Lips, cheeks, tongue, face skin.

\section{Point 9}

Using intraligamentary anesthesia bacteremia was observed in 50-97\%, and using infiltrative anesthesia-16\% [17]. Walton R, et al. [18] clarify that bacteremia occurs with intraligamentary injections not more often than with other dental procedures. Heizmann R, et al. [19] did not observe bacteremia for more than 10 years using the intraligamentary anesthesia in the clinic. Zugal W [20] writes about the same over a five-year period. Bacteremia with intraligamentary anesthesia is comparable to the frequency observed during tartar removal and curettage of the gum pockets. It is temporary. Antiseptic treatment of the gingival sulcus reduces bacteremia from $61 \%$ to $30 \%$ [21]. The skepticism of the injection is an important ethical problem of spongy anesthesia.

\section{Point 10}

The vascular spreading of epinephrine with spongy injections is another threat to the development of systemic sequeles. The analysis of our studies of sequeles (hypotensive (fainting, collapse) or hypertensive (crisis)) with spongy and classical anesthesia shows that reactions were slightly more often observed with spongy than classical injections. 
There is no data of serious systematic sequels in the dental literature except for the very early work of Boakes AJ, et al. [22] of 12 reports of the Committee on the Safety of Medicines (England) about severe adverse reactions of the use of dental anesthetics containing norepinephrine with a concentration of 1: 25000 . Interestingly, in 2 cases out of 12 , the reactions developed after performing a very rare at that time intraosseous anesthesia. The patients had excruciating headaches immediately after intraosseous injection within 4-5 minutes. One of them had a blackout of consciousness, memory, impaired speech for several days. We also observed 3 cases of severe and prolonged headache after 205 conducted intraligamentary anesthesia with articaine and epinephrine.

\section{Conclusion}

Considering the leading vascular component of the mechanism of spongy anesthesia and their effectiveness, relative safety, versatility of use, ease of implementation and the increasing prevalence in the world the traditional classification of local anesthesia should be modified. The essence of the modification is in the separation of all methods into diffusion and vascular diffusion.

\section{Funding}

No external funding was used for this project.

\section{Statement of Conflict of Interests}

As far as the authors are aware there was no conflict of interests.

\section{Contributions of Each Author}

Petrikas AZ planned the conceptual model for the study and its design, analyzed the results, approved the final version. Medvedev DV planned the conceptual model for the study and its design, administered the intraligamentary anesthesia and analyzed the results. Yakupova LA planned the conceptual model for the study and its design, administered the intraosseous anesthesia and analyzed the results. Efimova OE planned the conceptual model for the study and its design, administered the intraseptal anesthesia, and analyzed the results. Kulikova KV provided set of material Chestnyh EV provided set of material, analyzed the result. Sazonova KA provided set of material, translated the article.

\section{References}

1. Petrikas AZ (1987) Local anaesthesia of the pulp and hard dental tissues: Diss/Doc med Sciences Kalinin 413.
2. Yakupova LA (2006) Intraosseous dental anesthesia in experiment and clinic.

3. Medvedev DV (2011) Efficacy and safety intraligamentary anesthesia of the pulp and hard tissues of the tooth.

4. Efimova OE (2011) Intraseptal anesthesia of hard tissues and pulp of tooth: Technique, efficacy, complications.

5. Petrikas AZ, Chestnyh EV, Medvedev DV, Kuritsyna IU (2016) Classification of local anesthesia methods. Dent Oral Craniofac Res 2: 217-221.

6. Petrikas AZ (2009) Obezbolibanie v endodontie. MIA (Mosk).

7. Petrikas AZ (2013) Dental regional spongy (intraosseous) vascular anesthesia russ-engl.

8. Petrikas A, Lyapin MA, Kylikova KV, Kuritsyna IU (2017) Efficiency of $3 \%$ non-epinephrine mepivacaine application during intraligamentary anesthesia with positive and negative aspiration in pain sensitivity to electric current of young subject's upper anterior teeth pulp. J Oral Dent Health 1: 1-3.

9. AAE: Colleagues for excellence (2009) Alternative the solution the inferior alveolar nerve block. Bonus Material F.

10. Medvedev DV, Petrikas AJ (2009) Intraligamentary anesthesia of the lower posterior teeth. Dental 5: 21-23.

11. Glockmann E, Dirnbacher T, Taubenheim L (2005) Die intraligamentare anasthesie-alternative zur konventionellen lokalanasthesie? Quintessenz 56: 207-216.

12. Malamed SF (1982) The periodontal ligament (PDL) injection: An alternative to inferior alveolar nerve block. Oral Surg Oral Med Oral Pathol 53: 117-121.

13. Malamed SF (1997) Handbook of local anesthesia. (4 $4^{\text {th }}$ edn), Mosby.

14. Malamed SF (2004) Handbook of local anesthesia. $\left(5^{\text {th }}\right.$ edn), Elsevier/Mosby.

15. Malamed SF (2013) Handbook of local anesthesia. (6th edn), Elsevier.

16. Kim S (2002) Pulpal reaction to caries and dental procedures. In: Cohen S, Burn R, Pathways of the pulp. 573-600.

17. Roberts GJ, Simmons NB, Longhurst P, Hewitt PB (1998) Bacteremia following local anaesthetic injections in children. Br Dent J 185: 295-298.

18. Walton RE, Aboott BJ (1981) Periodontal ligament injection: A clinical evaluation. J Am Dent Assoc 103: 571-575.

19. Heizmann R, Gabka J (1994) Nutzen und grenzen der intraligamentären anaesthesie. Zahnärztl Mitt 84: 46-50.

20. Zugal W (2001) Die intraligamentare anasthesie in der zahnarztlichen praxis. Zahnarztl Mitt 91: 46-52.

21. Pashley D (1986) Systemic effects of intraligamental injections. J Endod 12: 501-504.

22. Boakes AJ, Laurence DR, Lovel KW, O'Neil R, Verrill PJ (1972) Adverse reaction to local anaesthetic-vasoconstrictor preparations. A study of the cardiovascular responses to xylestesin and hostacain-with-noradrenaline. $\mathrm{Br}$ dent $\mathrm{J} 133$ : 137-140.

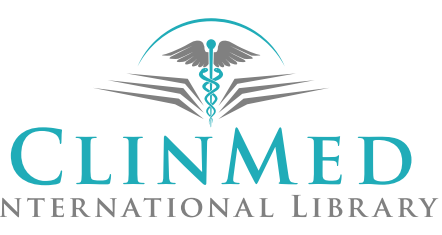

